\title{
The Removal of Tin from ITO-scrap via Ozonization
}

\author{
Jung-Chul Park \\ Department of Engineering in Energy \& Applied Chemistry, Green Fusion Technology Center, Silla Chiversitu, \\ Busan 617-736, Korea. E-mail: parkjciásilla ack \\ Received September 28, 2009, Accepted November t, 2009
}

Key Words: Removal. Tin. Indium. ITO. Ozonization

Indium is estimated to have an abundance in the earth 's crust of $0.05 \mathrm{ppm}$. which is similar to that of silver. As with other comparatively rare metals, indium becomes more concentrated in by-products arising during the extraction of major metals such as zinc. ${ }^{\text {l }}$

Consumption of indium is expected to increase throughout the next decade especially by dint of growth for liquid crystal displays, high-definition television. semiconductor materials. batteries. low-temperature solders and electronic application. Indium is used in various forms such as indium oxide/indiumtin oxide. indium metal and alloy. and indium compounds. ${ }^{2.3}$

Flat panel display applications for indium in the form of Indium Tin Oxide (ITO) are the most important end uses. more than one-half of the world's indium consumption. The glass plate coated with ITO which is formed by doping indium oxide with approximately $10 \%$ of tin oxide. exhibits electrical conductivity without significantly affecting transparency, and has been used as transparent electrodes for flat panel displays.

ITO films are generally fabricated by DC magnetron sputtering using ITO ceramic target. Magnetron sputtering is favoured because it is easily applied to large area with good uniformity. However. ITO targets should be replaced before a large portion of ITO material $(60 \sim 70 \%$ ) has been used because of race track formation. ${ }^{4-6}$ So, it might be said that the recycling of unused ITO target is indispensable as indium is a trace element and very expensive.

As shown in $\mathrm{In}_{1}{ }_{2} \mathrm{Sn}_{1} \mathrm{O}_{3}$ obtained by doping indium oxide with approximately $10 \%$ of tin oxide. tin is the major impurity in recovery process of indium metal from ITO target-scrap. Indium and tin are chemically very similar and separation one from the other in solution is a knotty problem. Rapid separation of indium from tin by sublimation has been reported. The procedure developed was based upon the volatility of indium acetylacetonate at moderate temperature. Another method concerns neutralization of solutions containing tin to $\mathrm{pH} 1$ followed by cementation with indium ${ }^{8.9}$ or by treating with $\mathrm{NaOH}$ to a $\mathrm{pH}$ value of $2.8^{10_{3}, 1 \mathrm{l}}$ Electrolytic recovery of indium from concentrated sulfate solutions has been suggested. ${ }^{12}$ A two-stage electrolytic procedure was proposed involving recovery of indium in apparatus with flat cathodes and complete extraction on the flow-through porous cathodes. Numerous investigators have studied to recover indium from solution by solvent extraction. ${ }^{13.14}$ The newly developed method to remove tin and purify indium metal from ITO target scrap has been reported using molten $\mathrm{NaOH}^{15}$

It is well known that ozone exhibits the strong oxidizing power. Therefore. $\mathrm{Sn}(\mathrm{II}) \mathrm{O} \times \mathrm{x}_{2} \mathrm{O}$ are easily oxidized to the higher oxidation state $\mathrm{Sn}(\mathrm{IV}) \mathrm{O}_{2} \cdot \mathrm{xH}_{2} \mathrm{O}$ in solution by ozonization.

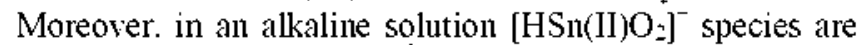
transformed into $\left[\mathrm{Sn}(\mathrm{IV}) \mathrm{O}_{3}\right]^{\hat{-}}$ by ozonization. In the recovery process of indium metal. Sn species are readily removed in a washing step. which gives rise to highly purified indium metal.

In this paper. we demonstrate a new method to remove tin and purify indium metal from ITO target scrap via ozonization.

\section{Experimental Section}

ITO target-scrap was obtained from Samsung Corning Co, Ltd. The sample was crushed and pulverized. The resulting powder was leached in $3 \mathrm{M} \mathrm{H}_{2} \mathrm{SO}_{4}$ solution at $80^{\circ} \mathrm{C}$ for $1.5 \mathrm{~h}$. and then filtered to renove undissolved materials. The obtained solution was treated with $\mathrm{NaOH}$, which resulted in suspension composed of metal hydroxide precipitates. The ozonization was performed using an ozonizer (Ozontech. LAB model) in this suspension. The ozonization was conducted for $2 \mathrm{~h}$ as a function of ozone concentration. The ozone concentration was verified with the variation of $\mathrm{O}_{2}$ flow rate $(0.5,1$, and 2 Liter per Minute (LPM)). For the recovery of purified indium metal. the indium sponge was obtained by cementation in sulfuric acid solution using aluminum plate $\left(\mathrm{pH} \approx 3,50^{\circ} \mathrm{C}\right.$ ). X-ray diffraction pattem of the recovered indium metal was achieved by Schmadzu 6000 model with $\mathrm{Cu}-\mathrm{K}_{x}$ radiation. The elemental analy sis was performed by inductively coupled plasma-emission spectroscopy (ICP) with Labtam 8400 model.

\section{Results and Discussion}

Table 1 shows the ICP elemental analysis result of ITO target-scrap as received. It reveals that ITO target composes a doping range of approximately $10 \%$ of tin oxide compared to indium oxide

The powder of ITO target scrap was leached using $3 \mathrm{M}$ $\mathrm{H}_{2} \mathrm{SO}_{4}$ at $80^{\circ} \mathrm{C}$ for $1.5 \mathrm{~h}$ and filtered to remove undissolved materials. The obtained solution was treated with $\mathrm{NaOH}$. which resulted in a suspended solution with metal lydroxide

Table 1. ICP elemental analysis of ITO target scrap as received

\begin{tabular}{cc|ccccccccc}
\hline \multicolumn{10}{c|}{ purity (\%) } & \multicolumn{10}{c}{ purity (ppm) } \\
\hline In1 & $\mathrm{S}_{n 1}$ & $\mathrm{Cr}$ & $\mathrm{Pb}$ & $\mathrm{Ni}$ & $\mathrm{Al}$ & $\mathrm{Zn}$ & $\mathrm{Cu}$ & $\mathrm{Cd}$ & $\mathrm{Fe}$ & $\mathrm{Mo}$ \\
\hline 74.84 & 7.50 & $<\mathrm{l}$ & $\mathrm{l}$ & $<1$ & $<1$ & $<1$ & 18 & $<1$ & 22 & $<1$ \\
\hline
\end{tabular}


Table 2. ICP elemental analysis of metal hydroxide precipitates after ozone (or. oxygen ) treatment"

\begin{tabular}{lccc}
\hline & $\operatorname{In}(\%)$ & Sn $(\%)$ & Sn removal $(\%)$ \\
\hline metal hydroxide precipitates after $\mathrm{O}_{2}$ treatment & 60.95 & 1.320 & 82.40 \\
metal hydroxide precipitates after $\mathrm{O}_{3}$ treatment & 60.87 & 0.016 & 99.79 \\
\hline
\end{tabular}

${ }^{a}$ The concentration of ozone: $11 \mathrm{~g} / \mathrm{h}$ (O. flow rate: 2 LPM).

Table 3. ICP elemental analy sis of the finally recovered indium metal

\begin{tabular}{|c|c|c|c|c|c|c|c|c|c|c|c|c|c|c|}
\hline purity $(\%)$ & & & & & & & puri & ppmi) & & & & & & \\
\hline In & $\mathrm{Sn}$ & $\mathrm{Cr}$ & $\mathrm{Pb}$ & $\mathrm{Al}$ & $\mathrm{Ti}$ & $\mathrm{Cd}$ & $\mathrm{Ni}$ & $\mathrm{Zn}$ & $\mathrm{Cu}$ & $\mathrm{Fe}$ & Mo & $\mathrm{Mg}$ & Mn & $\mathrm{Co}$ \\
\hline 99.96 & 231 & $<1$ & 5 & 7 & $<1$ & $<1$ & 36 & 13 & 16 & 50 & $<1$ & $<1$ & $<1$ & $<1$ \\
\hline
\end{tabular}

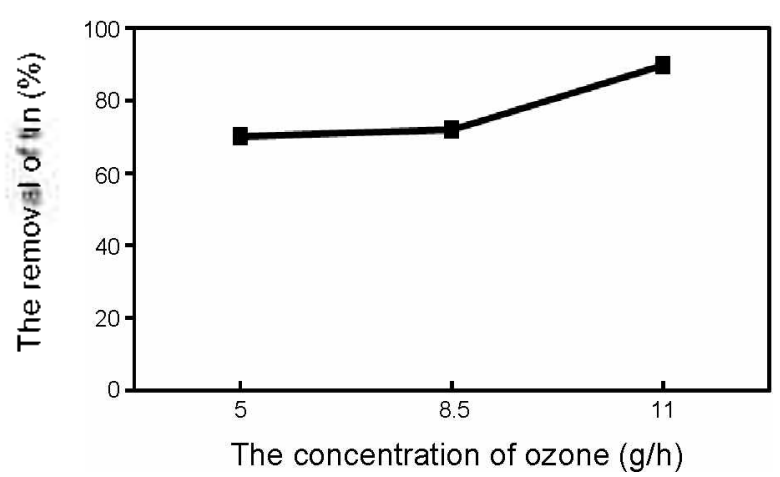

Figure 1. The Sn removal $(\%)$ of the metal hydroxide precipitates as a function of $\mathrm{O}_{3}$ concentration.

precipitates. The concentration of ozone was controlled and infised into the suspended solution for $2 \mathrm{~h}$. Figure 1 shows the Sn removal (\%) of the metal hydroxide precipitates as a function of $\mathrm{O}_{3}$ concentration. It reveals that the higher the concentration of ozone. the Sn removal $(\%)$ of the metal hydroxide precipitates higher

Based on the result of Sn removal via ozonization. it is recommended that the more effective $\mathrm{Sn}$ removal needs $\mathrm{HNO}_{3}$ dissolution of ITO scrap because $\mathrm{Sn}^{2+}$ species are easily transformed into amorphous stannic acid, $\mathrm{SnO}_{2} \cdot \mathrm{H}_{2} \mathrm{O}$ which is readily removed under filtering process. ${ }^{16}$ As shown in Table 2. the ozone treatment is more effective in Sn removal compared to oxygen. More especially, a considerable Sn removal (99.79\%) has been obtained in the ozone treated sample. The $\$$ n removal by ozone treatment can be expressed by following chemical equations:

$$
\begin{aligned}
& \mathrm{Sn}^{2-}+3 \mathrm{OH}^{-} \rightleftarrows\left[\mathrm{HSnO}_{2}\right]^{-}+\mathrm{H}_{2} \mathrm{O} \\
& {\left[\mathrm{HSnO}_{2}\right]^{-}+\mathrm{OH}^{-}+1 / 2 \mathrm{O}_{2} \rightleftharpoons\left[\mathrm{SnO}_{3}\right]^{--}+\mathrm{H}_{2} \mathrm{O}} \\
& {\left[\mathrm{HSnO}_{3}\right]^{-}+\mathrm{OH}^{-}+1 / 3 \mathrm{O}_{3} \rightleftharpoons\left[\mathrm{SnO}_{3}\right]^{2^{-}}+\mathrm{H}_{2} \mathrm{O}}
\end{aligned}
$$

As ozone exhibits the higher oxidizing power than oxygen. Sn(II) species are more effectively oxidized into Sn(IV) in an alkaline solution. Therefore, the finally stable $\left[\mathrm{SnO}_{3}\right]^{2-}$ can be easily removed. As $\mathrm{Na}_{2} \mathrm{SnO}_{3}$ is soluble in water and removed in a washing step high purity of $\operatorname{In}(\mathrm{OH})_{3}$ can be easily recovered. which is well coincident with Pourbaix E-pH diagram indicating that $\mathrm{Sn}(\mathrm{OH})_{2}$ and $\mathrm{Sn}(\mathrm{OH})_{4}$ transform into $\mathrm{HSnO}_{2}^{-}$ or $\mathrm{SnO}_{3}{ }^{2-}$ in an alkaline solution.

The resulting $\operatorname{In}(\mathrm{OH})_{3}$ powder was dissolved using $6 \mathrm{M}$ $\mathrm{H}_{2} \mathrm{SO}_{4}$ solution. Indium was recovered as sponge metal through cementation $w$ ith aluminum plate on the basis of standard reduction potentials $\left(\mathrm{E}^{\circ}\right.$ for $\mathrm{In}^{3+} / \mathrm{In}=-0.338 \mathrm{~V}, \mathrm{E}^{\circ}$ for $\mathrm{Al}^{3+} / \mathrm{Al}=$ $-1.68 \mathrm{~V}$ ) in $\mathrm{H}_{2} \mathrm{SO}_{4}$ solution with $\mathrm{pH}$ value of 1.5 at $60{ }^{\circ} \mathrm{C}$. Indium sponge metal is smelted at $400^{\circ} \mathrm{C}$ by excess $\mathrm{NaOH}$ which is used for preventing indium from oxidation and $a b-$ sorbing metal impurities. ICP analysis reveals that the purity of indiun metal is found to be approximately $99.96 \%$ without any further purification step.

Acknowledgments. I am grateful to GMS21 Co.. Ltd. for supplying ITO target scrap

\section{References}

1. Downs, A. T. Chemisty of Aluminm, Gallim, Indium and Thallium: London, 1993 ; pp. 89-90.

2. Ulrich, S. S.; Peter, M. H. Indium, Springer: Heidelberg, 2002; pp. 167-169.

3. Alfantazi, A. M.; Moskalyk, R. R. Minerals Engineering 2003. 16, 687 .

4. Guillen, C.: Herrero, I. Thin Solid Films 2006, 510, 260.

5. Yang, C. H.; Lee, S. C. Chen, S. C. Lin, T. C. Mtaterials Science and Engineering $B$ 2006. 129. 154 .

6. Hu, Y.:Dia, X.; Wang, C.; Wang, T. Tacum 2004, 75, 183.

7. Weiss, H. V.; Ballou, N. E.J. horg. Nitct. Chem 1965, 27, 1917.

8. Theurich. E. Freiberg. Forschnnsh. B 1963, 90,93

9. Muller, L. Freiberg. Forschungsh. B 1963, 90, 105

10. Hulsall, P. Trans. Inst. Metal. Sect C 1988, $97,93$.

11. Han, K. N.; Kondoju, S.; Park, K.; Kang, H. M. Geoststem Eng. 2002, 5(4), 93

12. Maslii, A. I.; Belobaba, A. G.; Vais, A. A. Applied Electro-chemistry and Corrosion Protection of hetals $1999,72,1108$.

13. Nishihama, S.: Hirai, T.: Komasawa, I. Ind. Eng. Chem. Res. 1999, 38,1032

14. Alguacil. F. J. Hydromet. 1999. 51.97.

15. Park, J. C. Bull Korew Chem. Soc $2008,29,255$.

16. Lide, David R. Hontbook of Chentistry and Phisics, CRC: 1990; B- 140

17. Pourbaix, M. Atlas D Equilibres Electrochintiques: Paris, 1963. 